\title{
Documento:
}

\section{Democratizar el espectro radioeléctrico}

El seminario "Democratizar el espectro radioeléctrico" reunió, en Pozo de Rosas,

Venezuela, del 11 al 15 de noviembre de 1996, a coordinadoras nacionales $y$ representantes de medios comunitarios de Argentina, Brasil, Chile, Colombia, Ecuador,

El Salvador, Guatemala, México, Paraguay, Uruguay y Venezuela; a abogados provenientes de varios países de la región, $y$ a directivos de las diez redes que integran el G-8: ALER, AMARC, CIESPAL, FELAFACS, FIP, PROA, RNTC, SCC, VIDEAZIMUT y

WACC, con el auspicio de la Fundación Friedrich Ebert de Alemania y el CECI de Canadá. Presentamos a continuación las conclusiones de este evento.

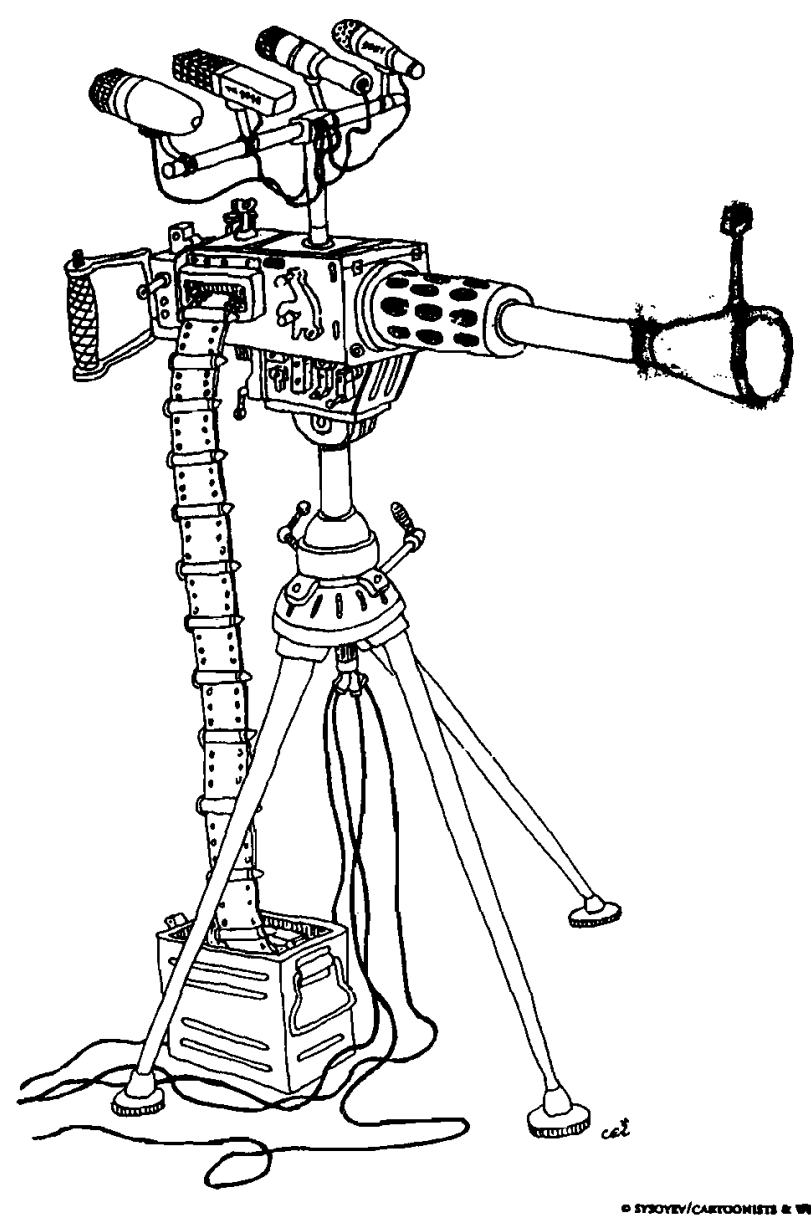

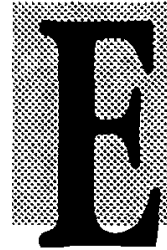
n el seminario se discutió un informe sobre la legislación de telecomunicaciones en la región e infor. mes nacionales de los paises representados. Se revisó el estado de los recursos de inconstitucionalidad, amparos y medidas análogas iniciados por radios comunitarias en Argentina, Ecuador, El Salvador, Brasil y Paraguay. Se analizó la legislación de los Estados Unidos de América y las normas internacionales del Sistema Interamericano de Derechos Humanos y de la Comisión de Derechos Humanos de las Naciones Unidas, asi como el Plan de Comunicación de la UNESCO y la iniciativa de cooperación con las ONG recibida de la Unión Internacional de Telecomunicaciones (UIT).

En consecuencia, los participantes aprobamos las siguientes conclusiones:

RATIFICAMOS nuestra plena adhesión a las conclusiones del seminario "El desarrollo de los medios de comunicación y la democracia en América y el Caribe", convocado por la UNESCO y el PNUD, en Santiago de Chile (mayo 1994), y a la Declaración del Festival de los Radioapasionados y Televisionarios, realizado en Quito (noviembre 1995).

ENTENDEMOS la radiodifusión como el ejercicio del derecho humano básico de expresión e información a través de un soporte tecnológico. El espectro radioeléctrico es un recurso natural limitado y patrimonio común de la humanidad. Los medios que representamos, de cuyas finalidades están excluidos el lucro y el proselitismo, se definen por un compromiso profundo con la legalidad democrática, el pluralismo, la diversidad de identidades culturales, el desarrollo sustentable y la paz. En este sentido, realizan una comunicación para la democracia y la paz, complementaria a la educación para la paz y a la cultura de paz. 
ENTENDEMOS la libertad de expresión e información, y su ejercicio, como fundamento esencial de la democracia. Esto implica promover acciones jurídicas y marcos regulatorios que reconozcan y aseguren la democratización del espectro radioeléctrico, el acceso y participación sin discriminaciones para todos los sectores (estatal, comercial y no comercial), la transparencia en la información sobre la gestión y administración del espectro y condiciones técnicas razonables para el otorgamiento y operación de los servicios de radio y televisión.

DETECTAMOS con preocupación, frente al surgimiento de emisoras de radio y televisión en manos de nuevos actores sociales (barriales, campesinas, sindicales, de mujeres, de indígenas, de jóvenes, universitarias, de diferentes denominaciones religiosas, etc.), la existencia de una campaña que busca eliminar del espectro radioeléctrico no solo a estos medios, sino también a los medianos y pequeños en un afán de monopolizar u oligopolizar la radiodifusión.

REAFIRMAMOS nuestra decisión de seguir contribuyendo a la democratización del espectro radioeléctrico sin excluir a nadie ni permitir medidas discriminatorias como el establecimiento de máximos de potencia o prohibiciones de publicidad que condenan a la asfixia financiera a los medios no comerciales.

SOMETEREMOS, en solidaridad con los medios comunitarios de otras regiones del mundo, estas situaciones irregulares, a los organismos regionales e internacionales competentes, entre ellos al Parlamento Latinoamericano, a la Red IFEX, auspiciada por la UNESCO, y a la recién constituida Plataforma Mundial sobre Comunicación y Democratización*.

DECLARAMOS, en este espiritu, nuestra disposición de utilizar todos los canales jurídicos, políticos e instituciona-

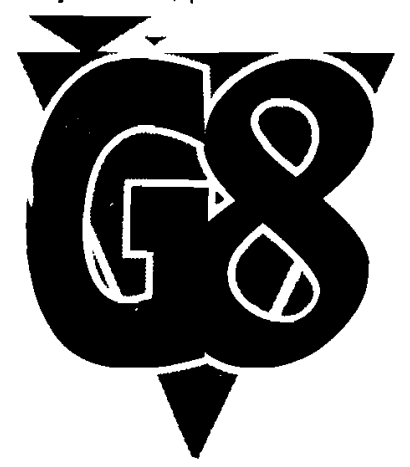

\section{RED LATINOAMERICANA DE DERECHO A LA INFORMACION (RELADI)}

En el seminario de Pozo de Rosas, un grupo interdisciplinario de profesionales de varios países latinoamericanos constituyeron la Red Latinoamericana de Derecho a la Información (RELADI) integrada por abogados, periodistas, técnicos, investigadores, docentes y personas interesa das en el desarrollo y democratizacion de las comunicaciones, como parte de la democratización de la sociedad latinoamericana, la paz y la justicia social

\section{Objetívos de la Red}

a. Mantener una interrelación permanente que nos permita el mutuo conocimiento de la legislación de nuestros paises y la de otras regiones, de sus cambios, de la doctrina y furisprudencla en la materia;

b. Propugnar, por la aplicacion de las normas internacionales de derechos humanos, la utilización de las instancias y herramientas del sistema internacional de protección de la libertad de expresión, de la libertad de información, de los derechos de los trabajadores de la comunicacion social y de los derechos humanos en general;

c. Desarrollar estudios comparados, debatir propuestas e impulsar la discusión de los medios para la optimización de la legislación que garantice el derecho a informar y ser informado;

d. Mantener relaciones con organizaciones no gubemamentales y gubernamentales que desarrollen actividades similares;

e. Crear y desarrollar una página interactiva en la WWW.

Para más información, comunicarse con:

Katia Gil, FIP

Calle Santos Erminy; Piso 7, Caracas, Venezuela

tel.: 582713778 , fax: 582711971

correo electrónico: fip@eldish,lat.net:

También con Damián Loreti, correo electrónico: rqloreti@criba.edu.ar.

Nota difundida por la Red IFEX, El intercambio internacional por la libertad de expresión.

490 Adelaide St. West, No. 205, Toronto ON MSV 1T2 Canadá

tel: 14167031638 . fax: 14167037034

correo electrónico: ifex@web.net

sitio internet: http://www.ifex.org/

les posibles para asegurar la legalidad democrática en el campo de las comunicaciones, y exhortamos a las organizaciones nacionales e internacionales a propiciar foros de encuentro entre los poderes legislativos, ejecutivos, los medios comerciales y comunitarios, asi como los sectores involucrados en la comunicación, a fin de que, con ánimo constructivo y de concertación, podamos asegurar la democratización de las comunicaciones en América Latina y el Caribe.
Caracas, Venezuela, 15 de noviembre de 1996.

\footnotetext{
- Red constituida el 1 de noviembre de 1996, en Londres, e integrada por las siguientes organizaciones: Article 19, Asso ciation for Progressive Communications, AMARC, Catholic Media Council, International Women's Tribune Centre, MacBride Round Table on Communications, Panos Institute, People's Communication Charter, Vidéazimut, WACC, Worldview International Foundation y Zebra.
} 